\title{
Acute abdominal pain in a young man
}

\author{
Haider M Al-Attia, Muna Al Murawy, Aysha Hareb, Omran B Gattee
}

A 25-year-old African man collapsed in the airport transit lounge while he was waiting to board the aircraft on his journey from an Asian country to his African home country. He developed severe abdominal pain that required his transfer to a nearby hospital as a possible case of acute pancreatitis. On arrival the abdomen appeared diffusely tender with a lower area of moderate guarding. Bowel sounds were normally audible. There were no scars seen externally, but there were sutures across the two sides of perineum, along with a few perineal ulcerations. The pupils were dilated. Multiple firm objects were felt on rectal examination. Some of these brown and sausage-shaped objects, were subsequently obtained by procto-sigmoidoscopy (figure 1). They measured $4-5 \mathrm{~cm} \times 1.5-2 \mathrm{~cm}$, and weighed $14-16 \mathrm{~g}$ each. Plain abdominal X-ray was taken on admission (figure 2).

Investigations including haemogram, electrolytes and urea, liver function test, serum amylase, Coomb's test, VDRL and serologic tests for HIV, gave normal or negative results. Anti-HB, Core $\mathrm{Ab}$, and $\mathrm{HBs} \mathrm{Ab}$ were positive. Stool examination showed hookworm and Schistosoma mansoni ova.

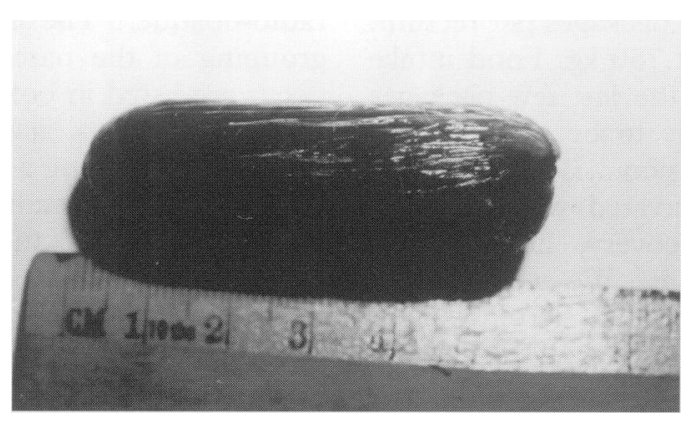

Figure 1 Brown sausage-shaped object obtained by procto-sigmoidoscopy

\section{Questions}

1 What does the plain abdominal X-ray show?

2 What is the most probable diagnosis?

3 What are the indications for surgical intervention in this condition?

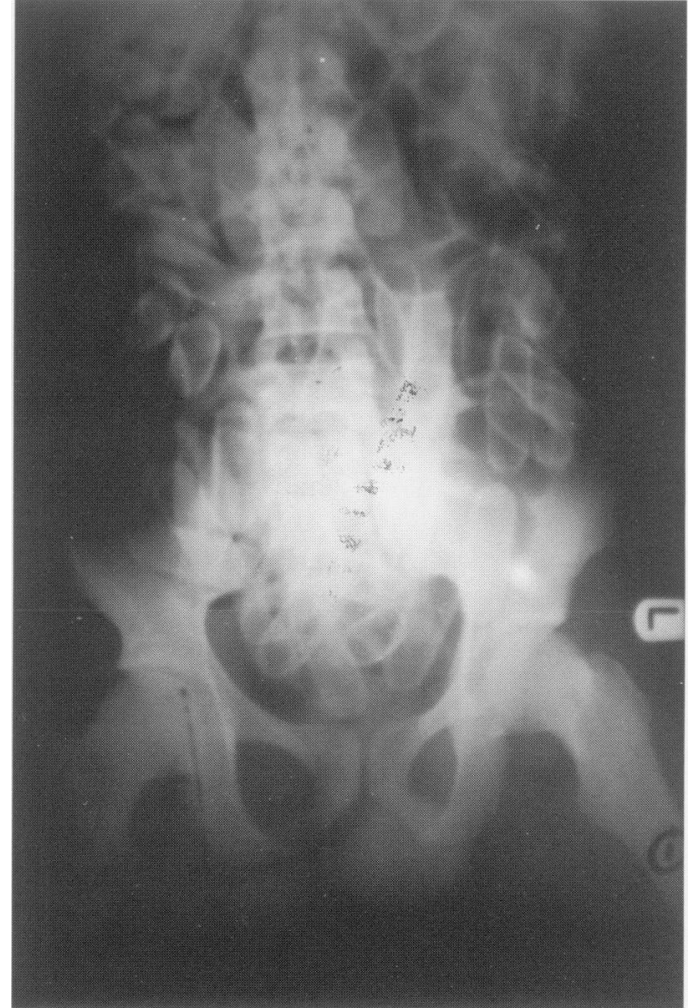

Figure 2 Plain abdominal X-ray 
Answers

\section{QUESTION 1}

The X-ray confirms the presence of many objects along the anatomical distribution of the large bowel. They are of heterogenous appearance with a radio-opaque outer coat and radiolucent inner part.

\section{QUESTION 2}

Body packer syndrome.

\section{QUESTION 3}

Surgery is indicated if obstruction occurs or if the packages being passed per rectum show signs of breaking up. Operation should also be considerated after resuscitating those who do not die following rupture of these packages. ${ }^{1-3}$

\section{Management}

The case was successfully managed with adequate fluid replacement and appropriate care of electrolytes along with repeated cleansing castile soap enemas at six-hourly intervals. Over a period of seven days, he passed a total of 113 heroin-containing packages per rectum. Their total weight was $1.750 \mathrm{~kg}$. Food intake was allowed only when the last few packages appeared radiographically to be clustering in the sigmoido-rectal region. Both parasitic infestations were duly treated with anti-helminthic agents. On recovery, he was discharged to police custody. We were denied further information on the total heroin weight, and the analysis of the fabric of the coat of these parcels. The patient did not reveal any information on the way he had acquired these parcels or the nature of surgical procedures he had endured.

\section{Discussion}

The body packer syndrome refers to the ingestion of multiple packages containing drugs for the purpose of transporting contraband. Usually, the 'body packers' or 'mules' use constipating agents in an attempt to pass through customs undetected. At a later stage, the parcels are expelled and the contents recovered. The gastrointestinal tract has been the main vehicle of illicit drug transportation. Another site of concealment is the vagina. The process carries considerable health risk and complications (box 1) have led to a fatal

\begin{tabular}{|l|}
\hline $\begin{array}{l}\text { Complications of 'body packer } \\
\text { syndrome' }\end{array}$ \\
\hline - rupture of parcels and leakage of drugs; \\
death may ocur from drug intoxication \\
- intestinal obstruction (6\%) \\
- intestinal perforation \\
\hline
\end{tabular}

Box 1

\begin{tabular}{|l|}
\hline Common areas of blockage of \\
packages \\
\hline - gastric outlet \\
- distal ileum \\
- ileocecal valve \\
- hepatic and splenic flexures \\
\hline
\end{tabular}

Box 2

outcome on many occasions. Nonetheless, with increasing experience of the organisers, the packing techniques have become more sophisticated and many survivors have now been reported. ${ }^{1-3}$

Previously, condoms, toy balloons or fingers of latex gloves were the fashion for packing, but they were highly susceptible to leakage or rupture and appeared either radiopaque or radiolucent on plain X-rays. ${ }^{1-5}$ More recently, packages made of layers of tubular latex with an additional layer of aluminium foil ${ }^{1}$ or cellophane $^{2}$ have been used. These are more resistant to leakage or rupture. Those with an aluminium coating are not visible on plain Xray, ${ }^{1}$ while most of the latter group appear radio-opaque. ${ }^{2}$ The common areas in which grouping of the parcels and gut obstruction occur are listed in box 2 .

The ingenious ways of transporting ilicit drugs are becoming a world-wide concern and the available pertinent medical literature from Europe, the US and Australia reflect the increasing awareness of the problem by medical personnel, particularly those with responsibility for nearby air or sea ports and prisons. $^{1-5}$

The case presented here demonstrates that there are no international borders to the extent of the problem. Though it was somewhat difficult to explain the presence of all these parcels at a single point of time in the large bowel only, it appeared unlikely to us that he had ingested such a large number of packages without developing vomiting, gut obstruction or perforation. It was highly probable that surgical expertise had been sought, and the parcels had been introduced through the rectum under general anaesthesia. Obviously the purpose of the perineal sutures was to block the anal opening, hence delaying the urge of rectal evacuation. Moreover, the heterogenous appearance of the parcels on X-ray film has not been reported previously. ${ }^{1-5}$

This case represents a new trend in corporeal transportation of contraband and this life like those of the other body packers, was regarded by the organiser(s) as entirely expendable.

\section{Final diagnosis}

A case of intracolonic heroin (body packer syndrome).

Keywords: body packer, heroin 
1 MaCaron MM, Wood JD. The cocaine "body packer" syndrome - diagnosis and treatment. $\mathcal{F A M A} 1983 ; 250$ : $1417-20$.

2 Caruana DS, Weinbach B, George D, Gardner LB. Cocainepacket ingestion. Ann Intern Med 1984; 100: 73-4.

3 Lancshire MJR, Legg PK, Lowe M, Davidson SA, Ellis BW.

Surgical aspects of international drug smuggling. $B M \mathcal{F}$ Surgical aspects of
$1988 ; 296,1035-7$.
4 Dassel PM, Punjabi E. Ingested marihuana filled balloons. Gasteroenterology 1979; 76, 166-9.

5 Horrocks AW. Abdominal radiography in suspected 'body packers'. Clin Radiol 1992; 45: 322-5.

\title{
An unusual neurological problem in a patient admitted for acute myocardial infarction
}

\author{
AD Kelion, M Shahi, JA Bell
}

Department of Cardiology, Battle Hospital, Oxford Road, Reading, Berks RG3 1AG, UK AD Kelion

M Shahi

JA Bell

Correspondence to $\mathrm{Dr}$ AD Kelion, Department of Cardiology, John Radcliffe Hospital, Oxford OX3 9DU, UK

Accepted 12 December 1996
A 70-year old man was admitted with unstable angina, and five days later was thrombolysed with intravenous streptokinase for an acute anterolateral myocardial infarction. After another four days he developed a frontal headache and photophobia, followed a few hours later by a sudden onset of complete ophthalmoplegia of the left eye, a complete left ptosis, and a fixed and dilated left pupil. No visual field defect or loss of visual acuity was evident. Computed tomography (CT) of the brain was reported as being unremarkable, although the cavernous sinuses were not properly visualised. The cerebrospinal fluid was clear with a protein level of $0.73 \mathrm{~g} / \mathrm{l}$.

On day 12 of the admission he became drowsy, pyrexial, and mildly hypotensive. Blood tests, electrocardiogram, chest X-ray, and echocardiogram remained unchanged, and an abdominal ultrasound scan was unremarkable. Urine and several sets of blood cultures were sterile. Following one unit of colloid, he was kept gently hydrated with intravenous crystalloid. He was treated for presumed sepsis with broad-spectrum antibiotics, and acyclovir was administered to cover the possibility of a Herpes simplex encephalitis. Unfortunately his condition remained unchanged, and on day 17 of the admission he developed acute pulmonary oedema and died a few hours later on the intensive care unit.

\section{Questions}

1 What was the diagnosis?

2 How might the diagnosis have been confirmed?

3 What was the appropriate management? 